\title{
Naltrexone fails to block shock-induced deficits in an appetitive discrimination task
}

\author{
DAVID M. GRILLY and GORDON C. GOWANS \\ Cleveland State University, Cleveland, Ohio
}

\begin{abstract}
Acute stress has been shown to induce analgesia-like effects in animals. However, little attention has been paid to other effects of these stressors, for example those on complex learned behaviors. Therefore, we assessed the effects of shock-induced stress on discrimination performance in rats and established whether any of the effects were opioid mediated. Rats were first trained in a two-lever, discrete-trial procedure in which brief light presentations were discriminative stimuli for food-reinforced leverpresses. After stable accuracy levels were achieved, the animals were injected (SC) with saline or the narcotic antagonist naltrexone (NALT) $(5.0$ or $20.0 \mathrm{mg} / \mathrm{kg}$ ), exposed to footshock $(2.5 \mathrm{~mA}$ for $30 \mathrm{sec}$ ), and then tested immediately afterward. Footshock significantly disrupted accuracy and increased choice and food-retrieval latencies. The accuracy deficits were found to be independent of the alterations in choice latencies. NALT failed to attenuate the accuracy deficits and accentuated the performance deficits. We proposed that some forms of acute shock exert nonopioid mediated dissociative effects that occur in conjunction with, and may be confounded with, alterations in nociceptive processes.
\end{abstract}

A variety of acute stressors have been shown to induce analgesia-like effects in animals (Akil et al., 1984). To determine if these effects involved opioid or nonopioid mediation, most of these studies have focused on parametric manipulations (Chatterjee \& Gebhart, 1984; Lewis, Terman, Shavit, Nelson, \& Liebeskind, 1984; Terman, Shavit, Lewis, Cannon, \& Liebeskind, 1984; Urca, Segev, \& Sarne, 1985; Watkins \& Mayer, 1982). However, little attention has been paid to other behavioral effects of these stressors. In investigating the behavioral properties of footshock and centrifugal rotation in rats, Hayes, Bennett, Newlon, and Mayer (1978) concluded that the analgesia induced by these stressors was not accompanied by generalized sensory, attentional, or motoric deficits. Their tests included: (1) observation of unrestrained locomotor and exploratory behavior; (2) evaluation of righting, placing, and corneal reflexes; (3) assessment of startle responses to loud sounds and air puffs; and (4) determination of the ability to orient to light tactile stimuli applied to vibrissae, trunk, and limbs. In an investigation of immobilization stress, Blair, Galina, Holmes, and Amit (1982) found that the analgesia induced was accompanied by a slight, but nonsignificant, decrease in locomotor activity in rats. Recent studies by Nabeshima and his associates (Nabeshima, Matsuno, \& Kameyama, 1985; Nabeshima, Yamada, \& Kameyama, 1983) have indicated that electric shock induces both analgesia and motor suppression in rats and mice.

This research was supported by a Research and Creative Activities Grant from Cleveland State University. The authors thank Katharine Altemus for her assistance in conducting this research. Requests for reprints should be sent to David M. Grilly, Bio-behavioral Research Laboratories, Department of Psychology, Cleveland State University, Cleveland, OH 44115.
There has been little investigation of the effects of analgesia-inducing stressors on complex learned behavior, although it has long been noted that exposure to intense electric footshock disrupts ongoing behavior (Azrin \& Holtz, 1966; J. S. Myers, 1971). A number of investigators have focused on the adaptive reactions of the organism to stress (Anisman, Hamilton, \& Zacharko, 1984; Fanselow, 1984; Fanselow \& Bolles, 1979; Grau, 1984) and have observed species-specific defense behaviors that could interfere with complex learned behavior. For example, in rats there is most commonly an initial burst of activity immediately following shock, which is followed by a period of partial to complete immobilization, sometimes referred to as "freezing" (Fanselow, 1984; J. S. Myers, 1971). Obviously, such effects are going to temporarily suppress positively reinforced instrumental behavior.

Investigators of the "learned helplessness" phenomenon have noted numerous performance decrements following inescapable shock (Anisman et al., 1984; Jackson, Alexander, \& Maier, 1980; Minor, Maier, \& Jackson, 1984; Rosellini, DeCola, \& Shapiro, 1982; Szostak \& Anisman, 1985). However, these studies have utilized multiple shock exposures, rather than a single shock exposure, to induce these effects.

Recent studies conducted in our laboratory (Grilly \& Gowans, 1986) have indicated that immobilization stress, which has been noted to induce analgesia-like effects (Amir \& Amit, 1978), also disrupts the accuracy of rats trained in appetitive discrimination tasks. In one task, the discriminative stimuli $\left(\mathbf{S}^{\mathrm{D}}\right)$ were mild shocks of different intensities, so the disruptions could have been attributable to the antinociceptive qualities of the treatment. However, similar effects were noted in a task in which the $S^{D}$ were brief light presentations. 
We are not aware of any studies of the effects of single, intense shock exposure (i.e., the type most commonly used to elicit analgesia) on appetitive choice behavior. Therefore, the purpose of the present study was to investigate the effects of brief footshock exposure on the foodreinforced performance of rats trained in a two-choice appetitive discrimination task. Since we anticipated that some behavioral deficits might occur following such a shock, we also attempted to determine if naltrexone (NALT), a narcotic antagonist that has been found to reduce shock-induced analgesia in some laboratories under some shock conditions (e.g., Chatterjee \& Gebhart, 1984; Lewis et al., 1984; Terman et al., 1984; Urca et al., 1985), might also reduce the behavioral deficits.

\section{EXPERIMENT 1}

\section{Method}

Subjects. Thirty three experimentally naive male $(N=21)$ and female $(N=12)$ Sprague-Dawley rats (bred at Cleveland State University) were used. They were 4 to 13 months of age $(M=$ 7.6 months) at the beginning of the experimental treatment phase of this study. At 100 days of age, their individual weights were determined and maintained at these levels $(M=330 \mathrm{~g}$, range $=$ 310-370 g) through food restriction. Water was available at all times in their cages. The animals were maintained in a $22^{\circ} \mathrm{C}, 50 \%$ humidity facility under a 12-h light-dark cycle (lights on $0800 \mathrm{~h}$ ). Test sessions were conducted between 1400 and $1800 \mathrm{~h}$.

Apparatus. Two Campden Instruments Ltd. operant chambers (Model 410, with dimensions of $24.5 \times 22.5 \times 20.0 \mathrm{~cm}$ ) were interfaced with an Apple II 64K microprocessor, which controlled experimental events and collected data. Two levers were located at one end of each chamber. The levers were $14.5 \mathrm{~cm}$ apart (center to center) and placed $6.7 \mathrm{~cm}$ above the grid floor. Each lever was $3.8 \mathrm{~cm}$ wide, $1.9 \mathrm{~cm}$ high, and $1.7 \mathrm{~cm}$ deep. The levers required $13.0 \mathrm{~g}$ of weight for contact closure. Located between the two levers and $1.0 \mathrm{~cm}$ above the grid floor was a food tray, into which single 45-mg food pellets (Bio-Serv dustless precision pellets) were delivered as reinforcers. A Plexiglas door covered the opening of the food tray and activated a microswitch when the rat's head was inserted into the opening. Three of the walls and the ceiling were aluminum; the fourth wall, through which the animal could be observed in a video monitor, was transparent Plexiglas. The grid floor consisted of stainless steel metal rods $(4.5 \mathrm{~mm}$ in diameter) spaced $1.5 \mathrm{~cm}$ apart. Constant-current ac shock generators (Lafayette Instruments, Model 82400) delivered shock through a shock scrambler (Lafayette Instruments, Model 82500), which presented shock pulses across any pair of grids twice per second. Lights directly above $(3.5 \mathrm{~cm})$ each lever and in the middle of the ceiling were activated by a $28-\mathrm{V}$ power source. All programming and recording equipment were located in an adjacent room.

Procedure. After leverpresses were shaped by successive approximations, the light discrimination procedure was implemented. During the sessions, the room lights were turned off. Trials began with the houselight in the chamber coming on for $1.7 \mathrm{sec}$. Prior to $S^{\mathrm{D}}$ presentation, the rat had to have its head out of the food tray and had to have refrained from pressing a lever for $1.0 \mathrm{sec}$. The light above one of the levers was then illuminated. A single press of the lever beneath the light resulted in $S^{D}$ light termination and food delivery (accompanied by a 40-msec light presentation inside the food tray). One second after the rat inserted its head in the food tray, the houselight was turned off. A single press of the other lever immediately terminated the trial, and all lights were turned off. Intertrial intervals were between 7.0 and $10 \mathrm{sec}$. The position of the light $S^{D}$ was random, except that there could be no more than six successive trials with the light present in the same position and, within a session, the total number of trials with each $S^{D}$ could not differ by more than two. When the animals reached a criterion of at least $90 \%$ correct in two successive 100 -trial sessions, the task was changed so that the $S^{D}$ lights were illuminated for $1.8 \mathrm{sec}$ and the first leverpress following $\mathrm{S}^{\mathrm{D}}$ termination was recorded. After the animals attained a criterion of $75 \%$ correct over four successive 100-trial sessions, they were randomly distributed into one of three drug dose groups.

On the first day of the experiment, $15 \mathrm{~min}$ prior to testing in a 120-trial session, the rats were injected (SC) with either saline or 5.0 or $20.0 \mathrm{mg} / \mathrm{kg}$ NALT (doses of naltrexone $\mathrm{HCl}$, which was graciously provided by NIDA, Division of Research, are expressed in terms of the salt). Five days later, the rats were administered the same drug treatment $15 \mathrm{~min}$ prior to the test session. After the 60th trial of the second test session, all rats were exposed to a 2.5-mA shock (constant-current ac scrambled shock to the feet) for $30 \mathrm{sec}$. These shock parameters were chosen on the basis of previous studies indicating that this form of shock induces a NALTsensitive analgesia in adult Sprague-Dawley rats (Terman et al., 1984). However, since subtle differences in the shock parameters used in different investigations can vastly alter the magnitude and form of analgesia (Chatterjee \& Gebhart, 1984; Lewis et al., 1984; Terman et al., 1984; Urca et al., 1985), our animals might not have exhibited a NALT-sensitive analgesia. Immediately after shock exposure, the rats' performance was assessed for $\mathbf{6 0}$ more trials. To preclude the possibility that any of our observations were dependent upon a specific characteristic of the procedure or animal, we conducted three variations of this general procedure. In the first variation, male rats ( $N=3$ per group) were exposed, on the shocktreatment day, to the shock approximately $10 \mathrm{sec}$ after the 60th trial in the operant chamber itself. In the second variation, on both of the test days, male rats ( $N=4$ per group) were removed from the operant chamber immediately following the 60 th trial, taken to a well-lit room next door (in which loud music was playing), placed on a shock grid, and covered with a Plexiglas cubicle (with dimensions slightly smaller than those of the operant chamber). On the first test day, these animals simply remained on the grid for $30 \mathrm{sec}$, and on the second day the shock was delivered. The animals were then returned to the operant chambers, and the test session was continued. The third variation was the same as the second except that female rats ( $N=4$ per group) were used. In no case were more than 2 animals tested on any single day.

\section{Results}

Since preliminary analyses had indicated that there were no significant differences across the three variations of this experiment (i.e., males shocked in the operant chamber, males shocked outside the chamber, and females shocked outside the chamber) with respect to the behavioral measures assessed, this variable was not included in subsequent analyses. The following behavioral measures were analyzed: (1) the time to the first response on the 61st trial of the two test sessions (used to assess how long it took the animals to resume responding after the shock); (2) percent correct responses; (3) mean choice latency (time between stimulus offset and leverpress); and (4) mean food retrieval latency (time between leverpress and food tray entry). For the latter two measures, all latencies greater than $10 \mathrm{sec}$ were set at a value of $10 \mathrm{sec}$. The last three measures were derived over 20 trial blocks so that any changes that may have occurred within the ses- 
sions could be assessed. Mixed analyses of variance (ANOVAs) were used for initial statistical analyses. Significant $F$ values were then followed up with planned comparisons (two-tailed $t$ tests) using Bonferroni $t$ test procedures (J. L. Myers, 1979, pp. 298-299). All individual comparisons involving the same mean square error term, derived through ANOVA techniques, were regarded as a family of contrasts with the error rate per family set equal to .05 .

The average time to the first response (i.e., the choice latency on the 61st trial) of the session without shock (control session) was $0.22,0.33$, and $0.36 \mathrm{~min}$ for the saline, and the 5- and $20-\mathrm{mg} / \mathrm{kg}$ NALT pretreated groups, respectively. Following the shock (shock exposure session), it was $13.72 \mathrm{~min}$ for the saline-treated rats, $23.40 \mathrm{~min}$ for the $5-\mathrm{mg} / \mathrm{kg}$-NALT-treated rats, and $29.70 \mathrm{~min}$ for the 20-mg/kg-NALT-treated rats. A two-way ANOVA revealed the presence of a significant session effect, that is, shock vs. no shock $[F(1,30)=86.1, p<.01]$, a significant drug treatment effect $[F(2,30)=3.98, p<.05]$, and a significant session $\times$ drug treatment interaction $[F(2,30)=3.77, p<.05]$. Differences between control and shock session were significant in all three drug treatment groups $[t \mathrm{~s}(10)=5.34,5.91$, and 5.46 , for saline, $5 \mathrm{mg} / \mathrm{kg}$ NALT, and $20 \mathrm{mg} / \mathrm{kg}$ NALT, respectively; $p \mathrm{~s}<.01$ ], and the $20-\mathrm{mg} / \mathrm{kg}-\mathrm{NALT}$ group differed significantly from the saline group in the shock session $[t(20)$ $=2.70, p<.02]$.

The effect of shock exposure on accuracy is depicted in Figure 1. Shock exposure decreased accuracy, with the greatest effect occurring in the first block of trials. A three-way ANOVA indicated that both the session effect $[F(1,30)=196.95, p<.001]$ and the session $\times$ block interaction $[F(2,60)=3.81, p<.05]$ were significant. A significant drug treatment effect $[F(2,30)=3.45, p<$ $.05]$ and a significant three-way interaction between ses-

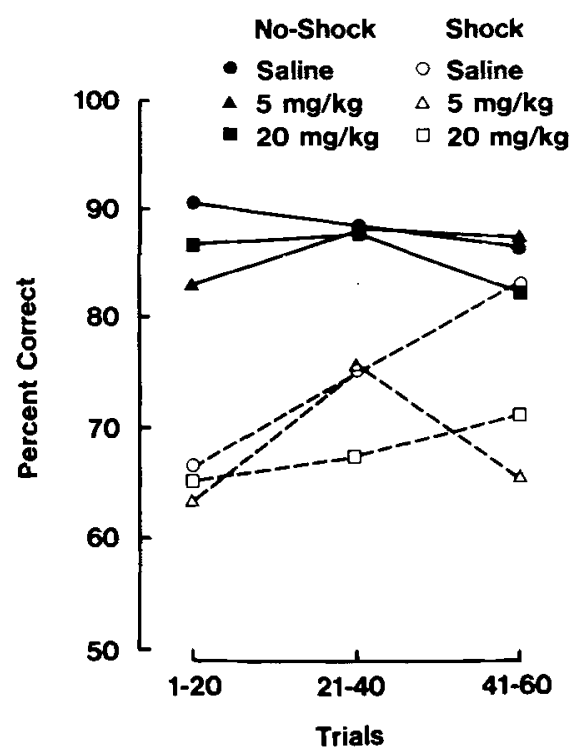

Figure 1. Effects of brief shock exposure on average percent correct in rats pretreated with saline or 5 or $20 \mathrm{mg} / \mathrm{kg}$ NALT.

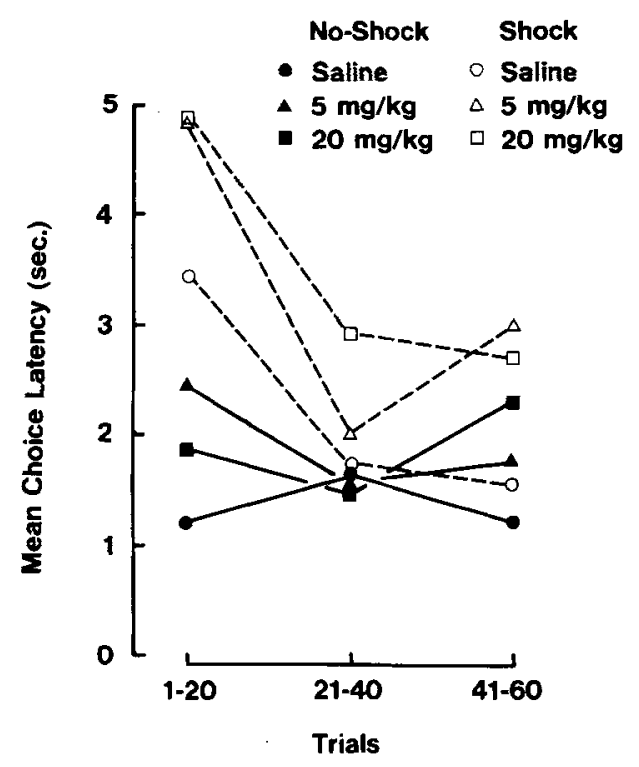

Figure 2. Effects of brief shock exposure on average choice latency in rats pretreated with saline or 5 or $20 \mathrm{mg} / \mathrm{kg}$ NAIT.

sions, trial block, and drug treatment $[F(4,60)=4.90$, $p<.005$ ] suggested that the NALT may have altered the effect of shock on accuracy. When ANOVAs were conducted separately for the control session data and the shock session data (with blocks and drug treatment as factors), the only significant effect noted was that for the block factor $[F(2,60)=4.81, p<.025]$ in the shock session. Thus, these separate analyses call into question the meaningfulness and reliability of the three-way interaction in the overall ANOVA and make tenuous any interpretation regarding the influence of NALT on the effects of shock exposure with respect to accuracy. Accuracy in the shock session was significantly below nonshock session levels in Blocks 1 and $2[$ ts $(10)=5.05$, $p<.001$, and $3.52, p<.01]$ for the saline group, in Blocks 1 and $3[t s(10)=6.73$ and $6.19, p s<.001]$ for the $5-\mathrm{mg} / \mathrm{kg}-\mathrm{NALT}$ group, and in Blocks 1 and 2 [ts $(10)$ $=4.16, p<.005$, and 7.71, $p<.001]$ for the 20 $\mathrm{mg} / \mathrm{kg}$-NALT group.

The effect of shock exposure on choice latency is depicted in Figure 2. Choice response latencies were considerably increased by shock exposure, and the effect appeared to be greater and longer lasting in the NALTtreated groups. A three-way ANOVA revealed that there were significant differences between sessions $[F(1,30)=$ $27.03, p<.001]$, among trial blocks $[F(2,60)=26.75$, $p<.001]$, and among drug treatment groups $[F(2,30)$ $=7.79, p<.005]$. In addition, there was a significant interaction between trial block and sessions $[F(2,60)=$ $15.29, p<.001]$ and between trial block and drug treatment $[F(4,60)=4.40, p<.005]$. ANOVAs conducted separately for the control session data and shock session data revealed that there were no significant drug treatment or block effects or interactions in the control session, but that there were a significant drug treatment ef- 
fect $[F(2,30)=3.79, p<.05]$ and a significant block effect $[F(2,60)=42.74, p<.001]$ in the shock session. Control-session levels were significantly different from shock-session levels in the first trial block $[t(10)=5.78$, $p<.001]$ for the saline group, in the first and third trial blocks $[t \mathrm{~s}(10)=4.50$ and $3.69, p<.005]$ for the 5 $\mathrm{mg} / \mathrm{kg}$-NALT group, and in the first block $[t(10)=4.98$, $p<.001]$ for the $20-\mathrm{mg} / \mathrm{kg}-\mathrm{NALT}$ group. In the shockexposure session, the saline group's choice latencies were significantly shorter than those of the $20-\mathrm{mg} / \mathrm{kg}$-NALT group $[t(20)=2.72, p<.02]$.

Shock exposure also significantly increased latency to retrieve the food reinforcers (depicted in Figure 3) in all groups, with the greatest effect being evidenced in the 20$\mathrm{mg} / \mathrm{kg}$-NALT-treated rats. A three-way ANOVA revealed significant main effects of trial block $[F(2,60)=13.14$, $p<.001]$, session $[F(1,30)=14.24, p<.001]$, and drug treatment $[F(2,30)=11.94, p<.001]$, as well as a significant interaction between session and drug treatment $[F(2,30)=3.54, p<.05]$. Separate ANOVAs for the control-session and shock-session data revealed that there were significant drug treatment effects in both sessions $[F \mathrm{~s}(2,30)=4.12$ and 4.66 , respectively; $p \mathrm{~s}<.05]$ and a significant block effect in the shock session $[F(2,60)$ $=13.03, p<.001$ ]. Shock-session food retrieval latencies differed significantly from control-session performance in all three groups $[t(10)=2.80, p<.02$, saline; $t(10)=3.60, p<.01,5 \mathrm{mg} / \mathrm{kg} \mathrm{NALT} ; t(10)=$ $3.06, p<.02,20-\mathrm{mg} / \mathrm{kg}-\mathrm{NALT}]$. The saline group differed significantly from the $20-\mathrm{mg} / \mathrm{kg}$-NALT group in both the control session $[t(20)=3.05, p<.01]$ and the shock session $[t(20)=2.80, p<.02]$.

We have found in previous work with this task that the probability of a correct choice is strongly related to the choice latency, that is, the longer it takes the animal to

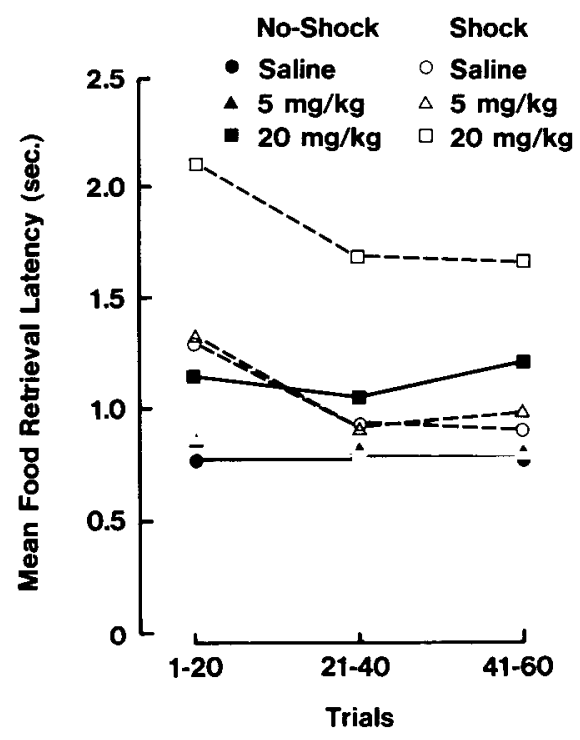

Figure 3. Effects of brief shock exposure on average food retrieval latency in rats pretreated with saline or 5 or $20 \mathrm{mg} / \mathrm{kg}$ NALT.

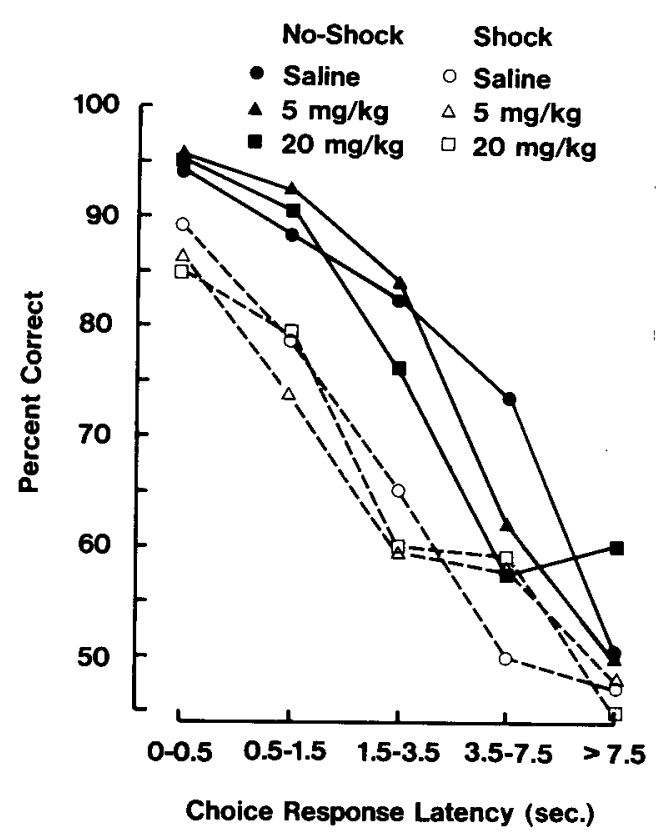

Figure 4. Effects of brief shock exposure on average percent correct as a function of choice response latency in rats pretreated with saline or 5 or $20 \mathrm{mg} / \mathrm{kg}$ NALT.

make a choice, the lower the probability of a correct choice. Therefore, it is possible that the accuracy deficits following shock exposure in these experiments were due to the longer latencies induced. To assess this possibility, percent correct was derived for each of five choicelatency categories: (1) $0.0-0.5 \mathrm{sec}$; (2) $0.5-1.5 \mathrm{sec}$; (3) 1.5-3.5 sec; (4) 3.5-7.5 sec; and (5) greater than $7.5 \mathrm{sec}$ (these categories were chosen because of the highly positively skewed distribution of the latencies).

Figure 4 shows the percent correct as a function of choice latency, session, and drug dose. It is apparent that shock exposure reduced accuracy in all categories except for those for which accuracy was already close to chance. A $2 \times 3 \times 3$ ANOVA, with factors of session, drug dose, and choice latency category (categories 1,2 , and 3 were used since percent correct was clearly above chance in these categories in the control session), indicated a significant session effect $[F(1,30)=63.21, p<.001]$, a significant choice category effect $[F(2,60)=22.25, p<$ $.001]$, and a significant session $\times$ choice category interaction $[F(2,60)=3.20, p<.05]$. Since the issue of whether accuracy and latency represent independent consequences of shock was particularly important, we also determined whether a reliable difference in accuracy remained after the variance attributed to latency differences was factored out by way of analysis of covariance. With choice latency treated as a covariate and condition (shock vs. no shock) and trials (60) as factors, there was still a highly reliable difference between the two conditions in percent correct $[F(1,32)=59.03, p<.001]$. Thus, these analyses indicate that shock exposure reduced accuracy independently of its effect on choice latency. 


\section{EXPERIMENT 2}

The results of Experiment 1 indicated that brief shock exposure induced deficits in accuracy and performance measures in an appetitive choice task. They further indicated that the performance deficits were accentuated by pretreatment with NALT, which has been shown to block opioid receptors at high doses (Chang \& Cuatrecasas, 1979; Chang, Hazum, \& Cuatrecasas, 1980). This would indicate that these shock-induced effects were not opioid mediated. However, several studies have suggested that the perceived noxiousness of shock is increased in rats pretreated with narcotic antagonists (Fanselow, 1984; Grau, 1984), which in turn enhances the rat's speciesspecific defense reactions (e.g., freezing). If activation of such reactions is a factor in decrements in learned behavior, it is possible that NALT accentuated the shockinduced effects found in Experiment 1 because it enhanced the perceived noxiousness of the shock (Turnbull, Hill, Miller, McElroy, \& Feldman, 1983; Whitehouse, Blustein, Walker, Bersh, \& Margules, 1985).

To assess this possibility, the conditions of Experiment 1 were replicated in Experiment 2, except that the rats were exposed to shock prior to CNS exposure to NALT. This was accomplished by the administration of NALT just prior to shock (the injection was given just before rather than just after shock to insure a uniform injection and to prevent injury to the animals while they were in a highly agitated state). Considerable evidence suggests that with this procedure the NALT would not enter the CNS until after shock termination. However, since NALT has been shown to reach peak levels in the rat brain at $30 \mathrm{~min}$ with $\mathrm{SC}$ injection (Misra, Bloch, Vardy, Mule, \& Verebely, 1976), sufficiently high levels of NALT would be expected to reach the brain during the 5-20-min period prior to the animals' resumption of responding following the shock. Also, we have found a reversal of morphine's disruptive effects on rats' performance in this task within 5 min after SC injection of NALT (unpublished observations).

\section{Method}

Subjects. Fourteen male Sprague-Dawley rats $(\boldsymbol{M}$ age $=11.9$ months, range $=11-13$ months) were used. They had been trained in the same task as in Experiment 1 and had been used in a previous study to assess the acute effects of $d$-amphetamine and NALT. In that study, they were exposed to several low doses (between 0.125 and $1.25 \mathrm{mg} / \mathrm{kg}$ ) of $d$-amphetamine and twice exposed to NALT $(10 \mathrm{mg} / \mathrm{kg})$. There was a minimum of 7 days $(M=20$ days $)$ between the animals' last drug exposure and the first test session of Experiment 2.

Apparatus and Procedure. The task and procedures were the same as in the second variation of Experiment 1, with the following exceptions. First, because of the rats' extensive experience in the task, the duration of the $S^{D}$ lights was decreased for some of the animals so that the overall accuracy levels of all animals was between $75 \%$ and $90 \%$ for four successive 100 -trial sessions (i.e., comparable to the levels of the animals in Experiment 1). Second, to determine the effects of the shock over a larger number of trials, the animals were placed in the shock apparatus (Test Session 1) or placed in the shock apparatus and administered shock (Test Ses- sion 2) after the 40th trial (rather than the 60th). Third, approximately $5 \mathrm{sec}$ prior to placement in the shock apparatus, half of the animals were injected (SC) with saline; the other half were injected with $5 \mathrm{mg} / \mathrm{kg}$ NALT.

\section{Results}

As in Experiment 1, shock exposure increased the average time to resume responding from $0.46 \mathrm{~min}$ (control session) to $12.51 \mathrm{~min}$ (shock session) in the saline group and from $0.26 \mathrm{~min}$ (control session)) to $24.75 \mathrm{~min}$ (shock session) in the NALT group. These differences were reflected in a significant dng treatment effect $[F(1,12)$ $=5.58, p<.05]$, a significant session effect $[F(1,12)$ $=51.43, p<.001]$, and a significant session $\times$ drug treatment interaction $[F(1,12)=5.96, p<.05]$. The NALT-treated group took significantly longer to resume responding following the shock than the saline group $[t(12)=2.40, p<.05]$.

Statistical analyses of the accuracy, choice latency, and food-retrieval latency data (depicted in Figures 5, 6, and 7 , respectively) revealed that there were significant differences between the control and shock-exposure sessions for all three measures $\left[F_{\mathrm{s}}(1,12)=20.30,20.50\right.$, and 13.50 , respectively, $p \mathrm{~s}<.005]$. None of the group or block effects in the control session were significant. In the shock session, significant block effects were observed in choice $[F(3,36)=10.88, p<.001]$ and food-retrieval latencies $[F(3,36)=6.72, p<.005]$, and a significant drug effect was observed with respect to choice latency $[F(1,12)=4.82, p<.05]$. In general, these results were quite similar to those observed in Experiment 1.

After the data analyses of Experiments 1 and 2 were conducted, the question arose as to whether the effects of acute shock exposure could have persisted beyond the exposure test session. Since the majority of animals in these experiments had been tested shortly after the shock exposure session, we had sufficient data to answer this question.

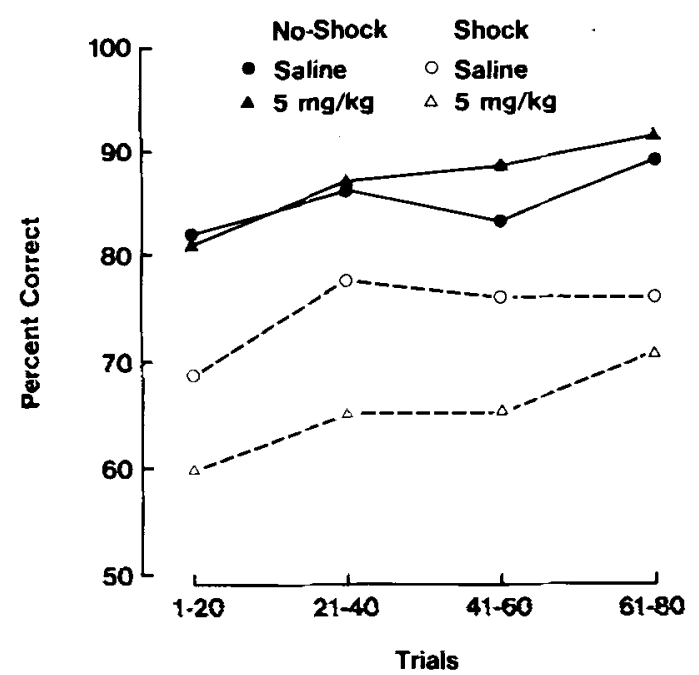

Figure 5. Effects of brief shock exposure on average percent correct in rats injected with saline or $5 \mathrm{mg} / \mathrm{kg}$ NALT immediately prior to shock. 


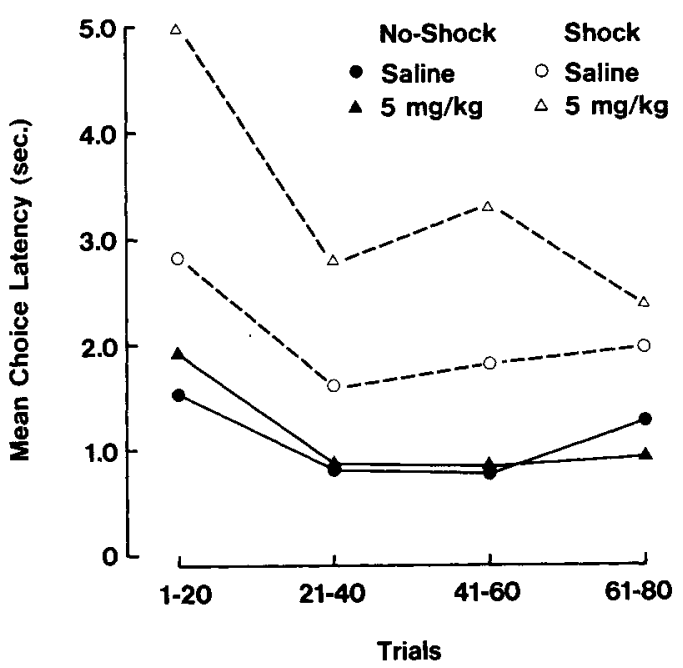

Figure 6. Effects of brief shock exposure on average choice latency in rats injected with saline or $5 \mathrm{mg} / \mathrm{kg}$ NALT immediately prior to shock.

Pre- and posttest accuracy scores were derived for each animal from the session immediately preceding the first test session and immediately following the second (shock exposure) test session. As a post hoc control condition, data were taken from 14 rats that had not been exposed to any drug or shock treatment but whose initial training was the same as that of the rats in Experiments 1 and 2. For each of these animals, we determined the point at which they reached a criterion of at least $75 \%$ correct for four successive sessions (the same criterion we used to determine when the animals of Experiment 1 were to begin experimental treatment). The percent correct in the last of these sessions was used as a "pretest" score. A "posttest" score was then based on performance in the third session following this criterion session (i.e., the first and second sessions following criterion were counterparts to the first and second experimental days of Experiment 1). A percentage change score $-[$ (post - pre)/pre $]$ $\times 100$-was then derived for each animal.

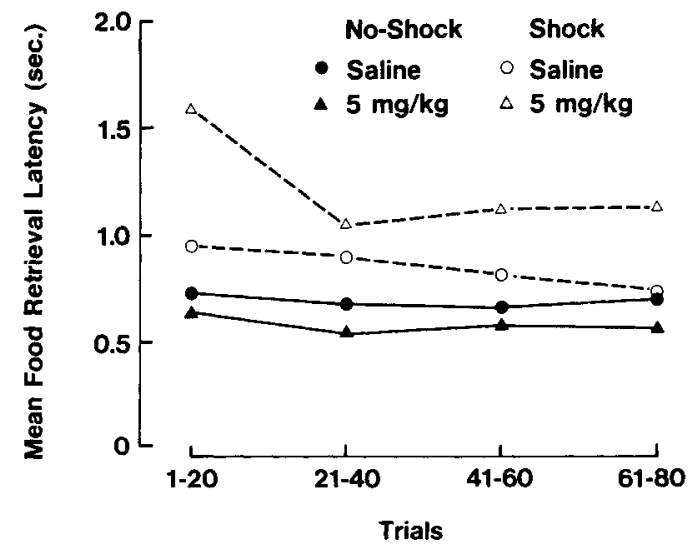

Figure 7. Effects of brief shock exposure on average food retrieval latency in rats injected with saline or $5 \mathrm{mg} / \mathrm{kg}$ NALT immediately prior to shock.
The number of days between the second experimental session and the posttest session was comparable for all groups $(M=4.2$, range $=1$ to 11$)$. Average percentage change was $-.44 \%$ for the unshocked control animals $(N=14),-.57 \%$ for the saline-treated, shocked animals $(N=16),-5.98 \%$ for the $5-\mathrm{mg} / \mathrm{kg}$-NALT-treated shocked animals $(N=15)$, and $-2.94 \%$ for the $20-\mathrm{mg} / \mathrm{kg}$-NALTtreated shocked animals $(N=10)$. Dunnett's test revealed that the 5-mg/kg-NALT group was significantly different from the unshocked control group $(p<.05)$. Thus, there was evidence that the effects of brief shock exposure in the $5-\mathrm{mg} / \mathrm{kg}$-NALT-treated animals persisted beyond the shock-exposure test session. Although the choice latencies for all the shock-exposed groups averaged somewhat longer in the posttest session than in the pretest session, none of the differences were statistically significant.

\section{DISCUSSION}

Numerous studies have noted that a variety of acute stressors induce an analgesia-like reaction in animals. While the vast majority of these studies have not reported other behavioral effects of these stressors, a few have suggested that stressors that produce analgesia in rats and mice have little or no effect on reactivity to stimuli, other than noxious ones (Blair et al., 1982; Hayes et al., 1978), but may decrease motility (Nabeshima et al., 1985; Nabeshima et al., 1983). On the other hand, many studies have shown that exposure to acute shock in rats typically results in a brief period of high activity followed by freezing, with a concomitant suppression of appetitive behavior (Azrin \& Holz, 1966; J. S. Myers, 1971). There is also considerable research that indicates that exposure to unsignaled shock classically conditions fear to contextual cues, which in turn disrupts operants maintained with positive reinforcement (Baker \& Mercier, 1982; Randich \& LoLordo, 1979). Although little attention has been paid to the effects of acute stressors on more complex learned behavior, a few studies have indicated that stressors such as immobilization (Grilly \& Gowans, 1986) and multiple shock exposure (Rosellini et al., 1982) can disrupt accuracy in appetitive choice tasks.

The results of the present study extend these observations by indicating that brief exposure to a shock, with parameters similar to those that induce short-lasting analgesia in rats (Chatterjee \& Gebhart, 1984; Terman et al., 1984), significantly disrupts both accuracy and performance measures in a two-choice discrimination task. The accuracy deficit was found to be independent of the shock-induced increase in choice latency. Contrary to previous studies that had shown opiate antagonist reversal of shock-induced analgesia (Chatterjee \& Gebhart, 1984; Terman et al., 1984) and motor suppression (Nabeshima et al., 1985; Nabeshima et al., 1983), the shock-induced effects noted in the present study were not blocked by either a moderate or high dose of NALT. Thus, these disruptions were not likely to have involved opioid mediation. In fact, with respect to all measures 
other than accuracy (i.e., time to resume responding following shock, choice latency, and food-retrieval latency), NALT tended to accentuate these deficits.

The results of the present study also indicate that brief shock exposure, at least when combined with NALT, may disrupt choice performance several days later. This phenomenon may be related to the findings of several studies in which increased retention of passive and active avoidance conditioning in rats is produced by posttraining administration of opiate antagonists (Gallagher, 1985). One interpretation is that performance in avoidance tasks is enhanced because of a greater degree of fear motivation. Thus, it would be reasonable to expect that fear elicitation (unconditioned or conditioned to the environmental context) would disrupt operants maintained by positive reinforcement (Baker \& Mercier, 1982; Randich \& LoLordo, 1979), although it is not clear whether this explanation would apply with respect to accuracy deficits in a choice task. Equally unclear is why NALT-enhanced fear would be responsible for the accuracy deficits in the postshock session but not in the shock session itself.

Numerous mechanisms through which shock exposure could disrupt choice behavior have been proposed. Several studies have noted that multiple exposures to shortduration (on the order of 2-5 sec) shocks can induce behavioral deficits in discrimination tasks involving aversive and appetitive motivation. However, there is disagreement about whether the deficits were due to disruptions in associative or nonassociative (e.g., attentional or motivational) processes. Using a Y-maze discrimination escape paradigm, Jackson et al. (1980) found that inescapable shocks disrupted accuracy even when the effects on latency were factored out, and concluded that an associative deficit was involved. In an appetitive context, Rosellini et al. (1982), who examined the effects of inescapable shock on accuracy and activity in a foodreinforced response choice-discrimination procedure, also concluded that the interference in accuracy was due primarily to associative factors. Our findings that the effect of brief shock on accuracy was independent of its effect on choice latency are consistent with an associative deficit interpretation. They also suggest that it is not necessary to expose animals to an extended series of inescapable shocks in order to produce the sort of accuracy deficits reported by Jackson et al. (1980) and Rosellini et al. (1982). Other studies have indicated that nonassociative factors, for example, attentional disturbances (Minor et al., 1984) or motor deficits (Sutton, Coover, \& Lints, 1981), may be involved. Anisman and his colleagues (Anisman et al., 1984; Szostak \& Anisman, 1985) have argued that stress-induced deficits may be due to the induction of response perseveration tendencies that could influence performance in various tasks.

Since shock was also found to affect our latency measures, it might be argued that shock has these consequences because it establishes a state of conditioned fear (cf. Baker \& Mercier, 1982; Randich \& LoLordo, 1979). It could then be argued that NALT augments conditioned fear because it intensifies the perceived noxiousness of shock (Fanselow, 1984; Fanselow \& Bolles, 1979; Grau, 1984). This interpretation is not supported by the results of White and Holtzman (1983), who found that doses of naloxone up to $10 \mathrm{mg} / \mathrm{kg}$ did not enhance suppression in a typical conditioned suppression paradigm. Furthermore, our results in Experiment 2 suggest that NALT can augment the effects of shock even when it does not enter the CNS until after shock exposure. This finding stands in contrast to the results of Fanselow and Bolles (1979) and Lester and Fanselow (1986). In both cases, they propose that a postshock injection of an opiate antagonist has little impact on conditioned fear.

As an alternative interpretation of our results, we propose that a generalized dissociative state (a term used to reflect a state in which the organism is disconnected from its environment and there is a general disruption in information processing) may be induced by some forms of acute stress. This, in turn, may be reflected in disruptions in not only the reactions of the organism to painful stimulation, that is, those measured in analgesia tests, but also in attentional, motivational, acquisition, and retrieval processes. Whether or not these effects are independent of each other will require further study. In this context, Thomas (1984) has noted that brainstem stimulation induced a generalized behavioral suppression that was not reversed with naloxone pretreatment and was independent of whether or not analgesia was induced, and Nabeshima et al. (1983) have suggested that different opioid receptors contribute to the analgesia and motor suppression induced by footshock in mice.

There has been considerable speculation that many of the stress-induced disruptions noted above are mediated by endogenous opioids. For example, the disruptions associated with multiple inescapable shock exposures have been reversed with NALT (Whitehouse et al., 1985; Whitehouse, Walker, Margules, \& Bersh, 1983). On the other hand, several studies, including ours, have indicated that some opiate antagonists may exacerbate the suppressive effects of shock on appetitively motivated operant behavior in rats. In experiments in which operants were maintained with food reinforcement, high doses of naloxone $(10 \mathrm{mg} / \mathrm{kg})$ have been found to enhance the suppressive effects of punishment (electric shock) while producing minimal suppressive effects (DeRossett \& Holtzman, 1985) or no effect (Young, 1980) on unpunished responding. In the DeRossett and Holtzman (1985) study, diprenorphine, an opioid antagonist with equally high affinity for $\mu$ and $\delta$ receptors (Sadee, Perry, Rosenbaum, $\&$ Herz, 1982), was found to have no effect on unpunished responding and significantly attenuated the suppressive effects of punishment. White and Holtzman (1983) found that naloxone (up to $10 \mathrm{mg} / \mathrm{kg}$ ) did not change the degree to which responding was suppressed during the preshock stimulus in a typical conditioned suppression paradigm, but that diprenorphine slightly attenuated conditioned suppression.

These findings are confounded by the fact that, by themselves, moderate to high doses of $\mu$-opioid-receptor antagonists suppress food and water consumption and 
primary goal-seeking behavior in rats (e.g., DeRossett \& Holtzman, 1985; Marks-Kaufman, Balmagiya, \& Gross, 1984; Sanger \& McCarthy, 1982; Schaefer \& Michael, 1981; Wagner, Masters, \& Tomie, 1984). Therefore, whether narcotic antagonists exacerbate or attenuate the disruptive effects of shock may be related to the degree to which the suppressive effects of shock are mediated by endogenous opioids, particularly at receptors other than the $\mu$ type. If the shock-induced effects are largely due to opioid activity, then narcotic antagonists may reduce the effects. On the other hand, if they are not mediated by opioids, and the effects are similar to those induced by narcotic antagonists, for example as in the present study, the effects of shock and narcotic antagonists may be functionally synergistic.

\section{REFERENCES}

AkIl, H., Watson, S. J., Young, E., Lewis, M. E., KhachatuRIAN, H., \& WALKER, J. M. (1984). Endogenous opioids: Biology and function. Annual Review of Neuroscience, 7, 223-255.

AMIR, S., AMIT, Z. (1978). Endogenous opioid ligands may mediate stress-induced changes in the affective properties of pain related behavior in rats. Life Sciences, 23, 1143-1152.

anisman, H., Hamilton, M., \& Zacharko, R. M. (1984). Cue and response-choice acquisition and reversal after exposure to uncontrollable shock: Induction of response perseveration. Journal of Experimental Psychology: Animal Behavior Processes, 10, 229-243.

Azrin, N. H., \& Holz, W. C. (1966). Punishment. In W. K. Honig (Ed.), Operant behavior: Areas of research and application (pp. 380447). New York: Appleton-Century-Crofts.

BAKER, A. G., \& MerCIER, P. (1982). Manipulation of the apparatus and response context may reduce the US pre-exposure interference effect. Quarterly Journal of Experimental Psychology, 34B, 221-234.

Blair, R., Galina, Z. H., Holmes, L. J., \& Amit, Z. (1982). Stress induced analgesia: A performance deficit or a change in pain responsiveness? Behavioral \& Neural Biology, 34, 152-158.

Chang, K. J., \& Cuatrecasas, P. (1979). Multiple opiate receptors: Enkephalins and morphine bind to receptors of different specificity. Journal of Biological Chemistry, 254, 2610-2618.

Chang, K. J., Hazum, E., \& Cuatracasas, P. (1980). Multiple opiate receptors. Trends in Neuroscience, 3, 160-162.

Chatterjee, T. K., \& Gebhart, G. F. (1984). Failure to produce a non-opioid foot shock-induced antinociception in rats. Brain Research, 323, 380-384.

DeRossetT, S. E., \& Holtzman, S. G. (1985). Effects of opiate antagonists and putative $\mathrm{k}$ agonists on unpunished and punished operant behavior in the rat. Psychopharmacology, 86, 386-391.

FANSELOW, M. S. (1984). Opiate modulation of the active and inactive components of the postshock reaction: Parallels between naloxone pretreatment and shock intensity. Behavioral Neuroscience, 98, 269-277.

FANSELOW, M. S., \& BoLLES, R. C. (1979). Naloxone and shock-elicited freezing in the rat. Journal of Comparative \& Physiological Psychology, 94, 736-744.

Gallagher, M. (1985). Re-viewing modulation of learning and memory. In N. M. Weinberger, J. L. McGaugh, \& G. Lynch (Eds.), Memory systems of the brain (pp. 136-162). New York: Guilford Press.

GraU, J. W. (1984). Influence of naloxone on shock-induced freezing and analgesia. Behavioral Neuroscience, 98, 278-292.

GrIlly, D. M., \& Gowans, G. C. (1986). Comparison of the effects of morphine and immobilization stress on discrimination performance of rats. Behavioral Neuroscience, 100, 512-524.

Hayes, R. L., Bennett, G. J., Newlon, P. G., \& Mayer, D. J. (1978). Behavioral and physiological studies of non-narcotic analgesia in the rat elicited by certain environmental stimuli. Brain Research, 155, 69-90.

Jackson, R. L., Alexander, J. H., \& Maier, S. F. (1980). Learned helplessness, inactivity, and associative deficits: Effects of inescapable shock on response choice escape learning. Journal of Experimental Psychology: Animal Behavior Processes, 6, 1-20.

LeSTER, L. S., \& FANSELOW, M. S. (1986). Naloxone's enhancement of freezing: Modulation of perceived intensity or memory processes? Physiological Psychology, 14, 5-10.

Lewis, J. W., Terman, G. W., Shavit, Y., Nelson, L. R., \& LiEBESKIND, J. C. (1984). Neural, neurochemical, and hormonal bases of stress-induced analgesia. Advances in Pain Research \& Therapy, 6, 277-287.

Marks-Kaufman, R., Balmagiya, T., \& Gross, E. (1984). Modifications in food intake and energy metabolism in rats as a function of chronic naltrexone infusions. Pharmacology Biochemistry \& Behavior, 20, 911-916.

Minor, T. R., MaIER, S. F., \& JACKSON, R. L. (1984). Effects of taskirrelevant cues and reinforcement delay on choice-escape learning following inescapable shock: Evidence for a deficit in selective attention. Journal of Experimental Psychology: Animal Behavior Processes, 10, 543-556.

Misra, A. L., Bloch, R., Vardy, J., Mule, S. J., \& Verebely, K. (1976). Disposition of $\left(15,16-{ }^{3} \mathrm{H}\right)$ naltrexone in the central nervous system of the rat. Drug Metabolism \& Disposition, 4, 276-280.

MYERS, J. L. (1979). Fundamentals of experimental design. Boston: Allyn \& Bacon.

MYERS, J. S. (1971). Some effects of noncontingent aversive stimulation. In F. R. Brush (Ed.), Aversive conditioning and learning (pp. 469-536). New York: Academic Press.

Nabeshima, T., MaTsuno, K., \& Kameyama, T. (1985). Involvement of different opioid receptor subtypes in electric shock-induced anaigesia and motor suppression in the rat. European Journal of Pharmacol$o g y, 114,197-207$.

Nabeshima, T., Yamada, K., \& Kameyama, T. (1983). Contribution of different opioid systems to footshock-induced analgesia and motor suppression. European Journal of Pharmacology, 92, 199-205.

RANDICH, A., \& LoLORDO, V. M. (1979). Associative and nonassociative theories of the UCS preexposure phenomenon: Implications for Pavlovian conditioning. Psychological Bulletin, 86, 523-548.

Roseluini, R. A., DeCola, J. P., \& Shapiro, N. R. (1982). Crossmotivational effects of inescapable shock are associative in nature. Journal of Experimental Psychology: Animal Behavior Processes, 8, 376-388.

Sadee, W., Perry, D. C., Rosenbaum, J. S., \& Herz, A. (1982). $\left({ }^{3} \mathrm{H}\right)$ Diprenorphine receptor binding in vivo and in vitro. European Journal of Pharmacology, 81, 431-440.

Sanger, D. J., M MCCARTHY, P. S. (1982). A comparison of the effects of opiate antagonists on operant and ingestive behavior. Pharmacology Biochemistry \& Behavior, 16, 1013-1015.

Schaefer, G. J., \& Michael, R. P. (1981). Threshold differences for naloxone and naltrexone in the hypothalamus and midbrain using fixed ratio brain self stimulation in rats. Psychopharmacology, 74, 17-22.

Sutton, B. R., Coover, G. D., \& LinTs, C. E. (1981). Motor debilitation, short- and long-term shuttlebox deficits, and brain monoamine changes following footshock pretreatment in rats. Physiological Psychology, 9, 127-134.

Szostak, C., \& ANisman, H. (1985). Stimulus perseveration in a water maze following exposure to controllable and uncontrollable shock. Behavioral \& Neural Biology, 43, 178-198.

Terman, G. W., Shavit, Y., Lewis, J. W., Cannon, J. T., \& LieBESKIND, J. C. (1984). Intrinsic mechanisms of pain inhibition: Activation by stress. Science, 226, 1270-1277.

ThомAs, A. J. (1984). Stimulation-produced analgesia and suppression of behavior in the rat. Physiological Psychology, 12, 285-292.

Turnbull, B. A., Hill, D. L., Miller, L. H., McElroy, J., * FeldMAN, R. S. (1983). Effect of high doses of naloxone on shuttle avoidance acquisition in rats. Pharmacology Biochemistry \& Behavior, $19,423-426$.

UrCA, G., SEgev, S., \& SARNe, Y. (1985). Stress induced analgesia: 
Its opioid nature depends on the strain of rat but not on the mode of induction. Brain Research, 343, 216-222.

WAGNER, G. C., MASTERS, D. B., TOMtE, A. (1984). Effects of phencyclidine, haloperidol, and naloxone on fixed-interval performance in rats. Psychopharmacology, 84, 32-38.

WATKINS, L. R., \& MAYER, D. J. (1982). Organization of endogenous opiate and nonopiate pain control systems. Science, 216, 1185-1192.

White, J. M., \& Holtzman, S. G. (1983). The effects of naloxone, diprenorphine, and diazepam on responding suppressed by pre-shock and pre-food stimuli. Life Sciences, 32, 479-486.

Whitehouse, W. G., Blustein, J. E., WAlker, J., Bersh, P. J., \& MARGULES, D. L. (1985). Shock controllability and opioid substrates of escape performance and nociception: Differential effects of peripherally and centrally acting naltrexone. Behavioral Neuroscience, 99, 717-733.

Whitehouse, W. G., Walker, J., Margules, D. L., \& Bersh, P. J. (1983). Opiate antagonists overcome the learned helplessness effect but impair competent escape performance. Physiology \& Behavior, 30, 731-734.

Young, G. A. (1980). Naloxone enhancement of punishment in the rat. Life Sciences, 26, 1787-1792.

(Manuscript received April 28, 1986;

revision accepted for publication January $6,1987$. ) 